\title{
Assessment of the Transmission System Operation Conditions through the Evaluation of Performance Index
}

\author{
Marialis Çelo ${ }^{1}$, Rajmonda Bualoti ${ }^{2}$ and Elio Voshtina ${ }^{3}$ \\ 1,2 Professor, Electric Engineering Faculty, Polytechnic University of Tirana, Albania. \\ ${ }^{3}$ Electric Engineer, Transmission System Operator, Albania.
}

ORCID: 0000 -0001-8897-945X (Marialis Celo)

\begin{abstract}
Transmission System Operational Security is one of the challenging tasks for power engineers and its managers. Transmission Systems are designed to fulfil N-1security criteria during operation. The operation of the transmission system in accordance with the operational security limits, in order to avoid emergency situations, or situations that could lead to partial system shut down or total system black outs, requires the continuous studying of the power system to verify different system scenarios and the fulfilment of the operational security limits for the Transmission System and the entire Power System. One of the most frequent studies as well as indicative ones about the Transmission System is the contingency analysis and fulfilment of N-1 criteria. Usually TSOs use SCADA system and EMS module, which perform a continuous security analysis based on the state estimator results. These analysis can be done, also off-line through power flow software. Contingency analysis require the study of the system before and post contingency, so a considerable volume of calculations has to be done including different scenarios of contingencies lines, generators, or nodes. A fast method to evaluate and rank contingencies which cause overloads in the transmission system is through performance indexes of active and reactive power. This article aims to provide the results of a study on the contingencies of Albania Transmission System. In the recent years the Albanian power system, had significant developments, i.e. the expansion and further penetration of small HPPs into the $110 \mathrm{kV}$ network, reinforcement of the $110 \mathrm{kV}$ grid through construction of the new lines on this voltage level, construction of $400 \mathrm{kV}$ lines etc.
\end{abstract}

Referring to the fact that Albania is still a net importer of the electricity, the recent development on power sector, under an updated legislation frame work has lead to less dependency from import, consequently the contingency analysis is very important to be done to identify the system constraints.

Keywords: Contingency analysis, N-1security criteria, contingencies ranking, performance index, TSO.

\section{INTRODUCTION}

Contingency ranking is one of the most important stages in the analysis of power system security. Complex power system mainly due to the economic and environmental pressures operates close to its limit of stability. This situation becomes worst when contingencies occur in the stressed power network Contingency Analysis is useful to detect network weaknesses and to plan and schedule maintenance or network expansion works. The most difficult methodological problem to cope within contingency analysis is the accuracy of the method and the speed of solution of the model used. The contingency analysis is used to predict the contingencies ranking according to their relative severity. The contingencies can be ranked based upon their effects on line loading or bus voltages. The literature reviews in contingency analysis gave information about many methods that can be used to perform the contingency analysis [1]. Most of contingency analysis algorithms performed the contingency selection in order to identify the worst cases for further analysis once the preventive and corrective measures have been identified [2]. There are two types of contingency analysis methods: a) contingency screening method based on a fast and approximate network solution [3] and b) contingency ranking method based on Performance Index (PI) [4]. Contingency screening for system reliability and a security assessment are examples of handling system uncertainties that can also take the form of uncertainties in: (i) forecasting; (ii) facility performances; (iii) power system contingencies; and (iv) market interactions [5]. The algorithm for automatic contingency analysis and ranking identify the potential harmful contingencies [6]. On-line contingency analysis requires evaluation and ranking of a large number of contingency cases in order to assess the static security of a power system [7]. There are fast methods for contingency ranking techniques using the Jacobian matrix manipulation in the load flow study [8] and other approaches, such as pattern recognition, neural network, genetic algorithm, etc [9]. The proposed algorithm has been tested on IEEE test power systems. The practical implementation of contingency screening can be done by installing the phasor measurement units which are being used to capture the online values of bus voltages and angles [10, 11]. Network security indices 
(voltage violation and line flow violation) and economic indices (location marginal price and congestion cost) have been considered to rank the contingencies [12]. Usually, planning in a deregulated environment involves the objectives of maintaining system reliability, minimising risks, improving market efficiency, minimising customer impact, and maximising profit [5]. It is also noted that the traditional n-1 criterion used in reliability assessment is inefficient in covering all the uncertainties in a deregulated environment.

Contingency selection criterion based on the calculation of performance indices has been first introduced by Ejebe and Wollenberg [12] where the values of performance index (PI) reflect the severity of the contingencies. Performance Index (PI) $[14,15]$ utilizes a wide system scalar performance index to quantify the severity of each case by calculating their PI values and ranking them accordingly their severity.

\section{STUDY MOTIVATION}

The N-1 security criterion is the first method of assessing the operational security of the power system. The definition of N1 security criterion [16] according to ENTSO-E Network Code Operational Security is: "The rule according to which elements remaining in operation within TSO's Responsibility Area after a Contingency from the Contingency List must be capable of accommodating the new operational situation without violating Operational Security Limits". This method applies the principle of removing an element from the power system and the system must have the ability to with stand the removal of that element, still being within operational security limits. The transmission network is constantly subject to changes, constraints, failures, physical flow changes, voltage changes, generation schedules adjustments (day ahead, intraday), load patterns, maintenances etc. All this processes must be planned and at the end the system should fulfil N-1 criteria. The state [16] of the network can be assessed with simulation software's before all these changes happened. The technique used is through power flow simulation, using Newton-Raphson/Fast-decoupled-load-flow technique. It is not the intention of this paper to go through this method. Nerveless of the powerful software solutions, running all the forecasted changes in the network with the aim of assessing the N-1 Security criterion, is a tedious and time consuming procedure. In this paper we proposed to use the Performance Index to tackle this issue. Basically the performance index will identify the contingency with the biggest impact on operational security limits, or even the contingency that will bring the blackout state.

The contingency selection is done by calculating two kinds of performance indices; active power performance index (PIP) for single transmission line outage, which has been done with the help of Fast Decoupled Load Flow (FDLF) in PSSE environment [17]. Also reactive power performance index
(PIV), can be calculated based on results power flow model for voltage and reactive power.

Based on the knowledge of PI \& PV the most severe transmission line contingency can be identified and the effect of this contingency on the rest of the system can also be seen via post contingency analysis.

In terms of system operation the knowledge of the critical element is crucial, before real-time operations, in order to ensure uninterrupted energy supply.

\section{ALBANIAN POWER SYSTEM}

The Albanian power System is a meshed network with a vertical profile and the current installed capacity of the country is around $2023 \mathrm{MW}$. While the major part of hydro generation facilities it is concentrated in the Northern part of the country, comprised of a total of $1403 \mathrm{MW}$ of the installed capacity in the Drin Cascade, the load is concentrated more in the centre and south part of the country leading to a physical flow direction from the northern part to the south [18]. The Transmission Network in Fig.1 has the following voltage levels: $400 \mathrm{kV}, 220 \mathrm{kV}, 154 \mathrm{kV}$ and $110 \mathrm{kV}$ and is well interconnected with other neighbour countries:

- 2 tie lines with Montenegro(400kV, 220kV)

- 2 tie line with Kosovo (400kV out of operation, $220 \mathrm{kV}$ )

- 2 tie lines with Greece $(400 \mathrm{kV}, 154 \mathrm{kV})$

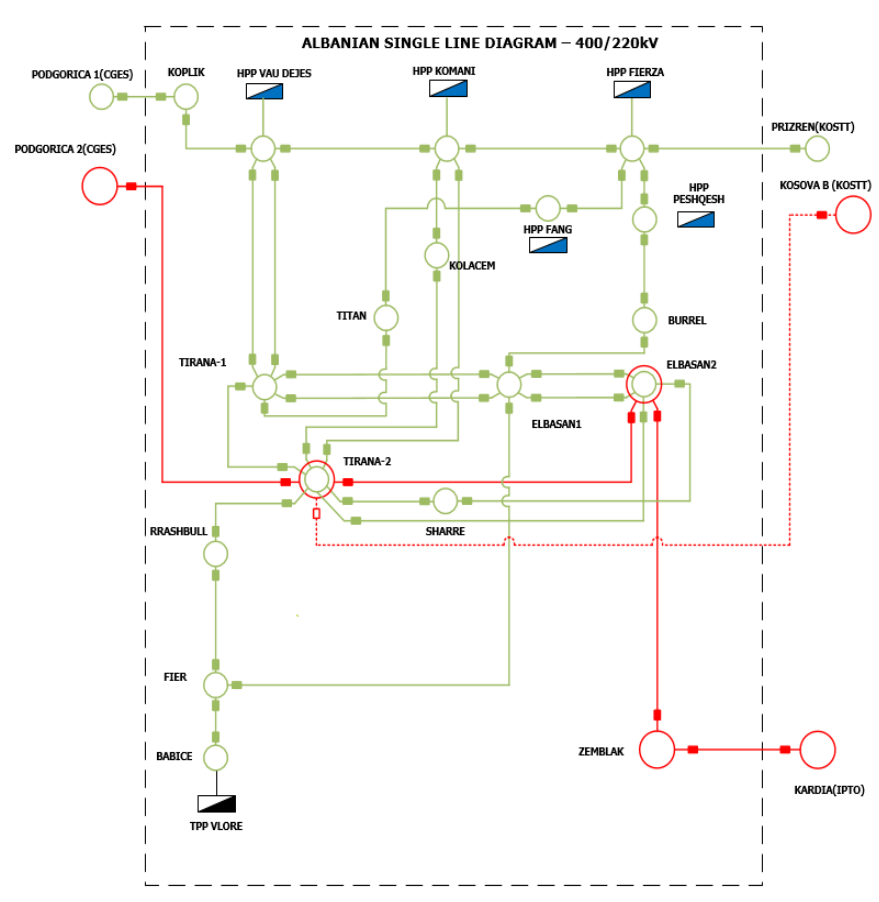

Fig. 1. Albanian Power System

In the north part of the country has large hydro generation capacities which are owned by the public power corporation 
KESH sh.a. The large hydro owned by KESH has an installed capacity of $1350 \mathrm{MW}$. Besides the large hydro's KESH owns also TPP Vlora, but because of technical issues the thermal power plant is out of operation. In the $220 \mathrm{kV}$ network there are connected also private HPPs owned by AYEN, namely Peshqesh (28MW) and Fang (72MW).

In the recent years there have been many run of river hydropower plants connected to the Albanian power system, whereas most of them have been connected into $110 \mathrm{kV}$ and distribution system. All this exploitations of Albanian rivers and consequently increase of installed generation capacity has led to a less dependent situation from imports for country adequacy. In the past years the adequacy was fulfilled mainly by firm import contracts performed by distribution company (OSHEE). Fig.2 shows the country energy balance for period 2005-2018. [19].

The new situation for the power system with a self-sustained $110 \mathrm{kV}$ network from the balance point of view, has changed the physical flows in the network, consequently in certain months of the year with high hydrology, the country has a positive balance exporting through the tie lines. This "exporting scenario" has to be studied, if the security criterion N-1 is fulfilled etc., considering that from the year 1994 the Albanian Power System was a net importer, meaning that also its development strategy was designed with the target of optimizing the network for accommodation of import flows.

Albanian country balance 2005-2018

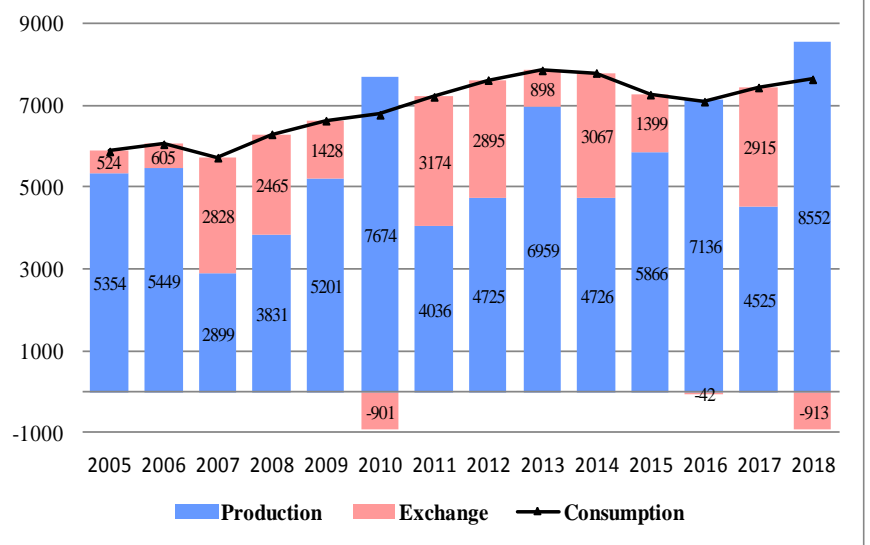

Fig. 2. Albanian country balance

Furthermore in the framework of implementation of deregulated energy market, with the presence of many participants on the power market mainly in the generation activities, assessing of the operational security of the power system and updating the list of contingencies is very important in the view of maintaining system reliability, minimising risks, improving market efficiency.
The security analysis currently used by the TSO is based on the day-ahead scenarios (D-1) and requires the following steps:

- Consider the network topological changes for D-1, generation, load, exchange (import / export)

- The production program is compiled

- The cross-border exchange program is harmonized taking into account trading transactions by energy market participants;

- Program is harmonized based on NTC (Net Transfer Capacity) values previously defined.

- Load forecast for the day in advance

- Determine the topology and state of all elements of the transmission system

All the steps described above serve as inputs to create the IGM (Individual Grid Model). Security analysis is done on the individual network model.

So, as can be seen from the above steps, system security analysis takes a relatively long time.

Analyzing system security using performance indexes gives us an opportunity to make a quick assessment of the state of the system in a given regime and contribute to give a clear picture of critical network elements and allowing us to take appropriate precautionary measures in order to avoid and minimize risks maintaining system security.

\section{CONTINGENCY RANKING METHODOLOGY}

Contingency ranking is defined based on the evaluation of performance index [PI]. Performance index formulation is based either or both the following criteria [20]:

\section{1) An overload criteria measuring branch loadings relative to their ratings.}

$$
P I=\sum_{i=1}^{L}\left(\frac{\mathrm{Pi}}{\mathrm{PMAX}_{i}}\right)^{2}
$$

Where:

$\mathrm{Pi} \quad$ is the active power flow on branch $\mathrm{i}$.

PMAXi is the rating of branch $i$.

$\mathrm{L} \quad$ is the set of monitored branches contributing to PI.

The formula is intuitive by itself, indicating that a small value of PI will be obtained for unloaded elements, and a greater value will be obtained for loaded elements or when elements exceed their limits. If the PI increases after a contingency, it shows that the contingency contributes to the overall loading of the elements. 
2) A voltage decrease criteria that indicates increased reactive power consumption by estimating increases in reactive losses due to increased line loadings.

$$
P I=\sum_{i=1}^{L} X_{i} * P_{i}^{2}
$$

Where:
$\mathrm{Xi} \quad$ is the reactance of branch $\mathrm{i}$.
$\mathrm{Pi} \quad$ is the active power flow on branch $\mathrm{i}$.
$\mathrm{L} \quad$ is the set of monitored branches contributing to PI.

Formula (2) gives an indication of reactive power losses in the transmission system. While line loading increase, the $I^{2} X$ losses will increase. An increase in reactive power consumption will results in reduction of nodes voltages.

PI is calculated using formula (1) or (2) separately. More accuracy can be achieved by using both formulas to represent combined Performance Index.

The index is calculated based on the number of element, through running a power flow each time after removal of an element from the network, and every time the index is calculated representing the specific weight of that particular element in power system security criterion $\mathrm{N}-1$. The calculation stops, when the iterative process reaches the maximal number of elements. All PI indexes are order in a list, starting with the element with greatest value, up to the lowest value.

\section{THE MODEL}

The Transmission system has been modelled up to $110 \mathrm{kV}$, except the generators which have been modelled to the bus bar voltage. All the load and generation below the voltage level of $110 \mathrm{kV}$ has been modelled to $110 \mathrm{kV}$ voltage level. The system is made of 138 nodes, 40 generating units (including tie lines which are modelled also as generating units), 149 lines, 50 two winding transformers, 1 shunt reactor, 2 compensators, 88 loads. The model only uses direct sequence parameters. The analysis has been performed using PSSE [17] software from Siemens, version 33.1.

\section{SIMULATIONS SCENARIO}

In order to achieve reliable results, the analysis has been based on metered data, with the assumption that the metered data with a mean value of $15 \mathrm{~min}$, represent the best possible estimate of a snapshot of the system state.

The analysis has been performed for 6 scenarios, as in the following Table 1, mainly with different export values and also for the balancing scenario.

Table 1. Simulation scenarios

\begin{tabular}{|c|c|c|c|c|}
\hline & $\begin{array}{c}\text { Load } \\
(\mathrm{MW})\end{array}$ & $\begin{array}{c}\text { Generation } \\
(\mathrm{MW})\end{array}$ & $\begin{array}{c}\text { Interchange } \\
(\mathrm{MW})\end{array}$ & $\begin{array}{c}\text { Losses } \\
(\mathrm{MW})\end{array}$ \\
\hline Scenario A & 770 & 1344 & +520 & 54 \\
\hline Scenario B & 770 & 1154 & +350 & 34 \\
\hline Scenario C & 770 & 1103 & +300 & 33 \\
\hline Scenario D & 770 & 1065 & +264 & 31 \\
\hline Scenario E & 770 & 1002 & +205 & 27 \\
\hline Scenario F & 770 & 790 & 0 & 20 \\
\hline
\end{tabular}

\section{CONTIGENCY ANALYSIS, PI EVALUATION}

Convergent power flow solutions were obtained, after defining the 6 scenarios to be studied, in order to calibrate the accuracy of power flows model in the software PSS/E. The results of the power flow solution were compared also with SCADA measured valued, with the aim to gain confidence that the model is accurate enough for further analysis. The next step was done by using the formula (1) for the estimation of PI indexes for each network element, and the results obtained are shown below.

\section{Scenario A}

\begin{tabular}{|c|l|r|r|}
\hline \multicolumn{4}{|c|}{ EXPORT 520MW } \\
\hline Voltage & \multicolumn{1}{|c|}{ Bus 1 } & \multicolumn{1}{c|}{ Bus 2 } & \multicolumn{1}{c|}{ PI } \\
\hline $400 \mathrm{kV}$ & ELBASAN2 & ZEMBLAK & 227.1326 \\
\hline $400 \mathrm{kV}$ & ELBASAN2 & TIRANA2 & 14.9881 \\
\hline $220 \mathrm{kV}$ & FIERZE & TITAN & 14.8166 \\
\hline $220 \mathrm{kV}$ & BURREL & ELBASAN1 & 14.6592 \\
\hline $220 \mathrm{kV}$ & TIRANA2 & RRASHBULL & 14.5251 \\
\hline $220 \mathrm{kV}$ & TIRANA2 & TITAN & 14.2854 \\
\hline $220 \mathrm{kV}$ & ELBASAN1 & FIER & 13.7965 \\
\hline $220 \mathrm{kV}$ & KOMAN & TIRANA2 & 13.6990 \\
\hline $220 \mathrm{kV}$ & BURREL & PESHQESH & 13.6856 \\
\hline $220 / 110 \mathrm{kV}$ & FIERZE220 & FIERZE110 & 13.5381 \\
\hline
\end{tabular}




\section{Scenario B}

\begin{tabular}{|c|l|l|c|}
\hline \multicolumn{4}{|c|}{ EXPORT 350MW } \\
\hline Voltage & \multicolumn{1}{|c|}{ Bus 1 } & \multicolumn{1}{|c|}{ Bus 2 } & PI \\
\hline $400 \mathrm{kV}$ & ELBASAN2 & ZEMBLAK & 57.8166 \\
\hline $220 \mathrm{kV}$ & BURREL & ELBASAN1 & 14.4895 \\
\hline $220 \mathrm{kV}$ & TIRANA2 & RRASHBULL & 12.8292 \\
\hline $220 \mathrm{kV}$ & KOMAN & TIRANA2 & 12.2944 \\
\hline $220 \mathrm{kV}$ & ELBASAN1 & FIER & 12.2136 \\
\hline $220 \mathrm{kV}$ & KOMAN & KOLACEM & 12.0882 \\
\hline $220 \mathrm{kV}$ & KOLACEM & TIRANA2 & 12.0646 \\
\hline $220 \mathrm{kV}$ & FIERZE & TITAN & 12.0576 \\
\hline
\end{tabular}

Scenario C

\begin{tabular}{|c|l|l|c|}
\hline \multicolumn{4}{|c|}{ EXPORT 300MW } \\
\hline Voltage & \multicolumn{1}{|c|}{ Bus 1 } & \multicolumn{1}{|c|}{ Bus 2 } & PI \\
\hline $400 \mathrm{kV}$ & ELBASAN2 & ZEMBLAK & 90.3196 \\
\hline $220 \mathrm{kV}$ & BURREL & ELBASAN1 & 13.9997 \\
\hline $220 \mathrm{kV}$ & TIRANA2 & RRASHBULL & 12.3111 \\
\hline $220 \mathrm{kV}$ & ELBASAN1 & FIER & 11.8113 \\
\hline $400 \mathrm{kV}$ & ELBASAN2 & TIRANA2 & 11.6723 \\
\hline $220 \mathrm{kV}$ & KOMAN & TIRANA2 & 11.5523 \\
\hline
\end{tabular}

\section{Scenario $D$}

\begin{tabular}{|c|l|l|c|}
\hline \multicolumn{4}{|c|}{ EXPORT 264MW } \\
\hline Voltage & \multicolumn{1}{|c|}{ Bus 1 } & \multicolumn{1}{|c|}{ Bus 2 } & PI \\
\hline $400 \mathrm{kV}$ & ELBASAN2 & ZEMBLAK & 33.5655 \\
\hline $220 \mathrm{kV}$ & BURREL & ELBASAN1 & 14.6279 \\
\hline $220 \mathrm{kV}$ & TIRANA2 & RRASHBULL & 12.9157 \\
\hline $220 \mathrm{kV}$ & KOMAN & V.DEJES & 12.1507 \\
\hline $220 \mathrm{kV}$ & ELBASAN1 & FIER & 12.0122 \\
\hline $220 \mathrm{kV}$ & FIERZE & TITAN & 11.8603 \\
\hline $220 \mathrm{kV}$ & KOMAN & TIRANA2 & 11.8282 \\
\hline $220 \mathrm{kV}$ & TIRANA2 & TITAN & 11.7484 \\
\hline & & & \\
\hline
\end{tabular}

Scenario $E$

\begin{tabular}{|c|l|l|c|}
\hline \multicolumn{4}{|c|}{ EXPORT 205MW } \\
\hline Voltage & \multicolumn{1}{|c|}{ Bus 1 } & \multicolumn{1}{|c|}{ Bus 2 } & PI \\
\hline $400 \mathrm{kV}$ & ELBASAN2 & ZEMBLAK & 47.1057 \\
\hline $220 \mathrm{kV}$ & BURREL & ELBASAN1 & 12.8324 \\
\hline $220 \mathrm{kV}$ & TIRANA2 & RRASHBULL & 12.1082 \\
\hline $220 \mathrm{kV}$ & ELBASAN1 & FIER & 11.1938 \\
\hline $220 \mathrm{kV}$ & KOMAN & TIRANA2 & 10.7753 \\
\hline
\end{tabular}

\section{Scenario $F$}

\begin{tabular}{|c|l|l|c|}
\hline \multicolumn{4}{|c|}{ BALANCE } \\
\hline Voltage & \multicolumn{1}{|c|}{ Bus 1 } & \multicolumn{1}{|c|}{ Bus 2 } & PI \\
\hline $220 \mathrm{kV}$ & TIRANA2 & RRASHBULL & 7.1872 \\
\hline $400 \mathrm{kV}$ & ELBASAN2 & ZEMBLAK & 7.1562 \\
\hline $220 \mathrm{kV}$ & ELBASAN1 & FIER & 6.8296 \\
\hline $220 \mathrm{kV}$ & KOMAN & TIRANA2 & 6.1722 \\
\hline $220 \mathrm{kV}$ & FIER & RASHBULL & 6.1581 \\
\hline
\end{tabular}

Analyzing the results obtained it is noticed that all $220 \mathrm{kV}$ network elements, have more or less similar PI indexes, meaning that their impact in the network is the same. While the $400 \mathrm{kV}$ OHL Elbasan-Zemblak tends to have a higher value while export is increased. The key variable here is the export value. In low export scenarios the index PI, has a low value, while with the increase of export value, the index PI increases, i.e. an increase of $170 \mathrm{MW}$ in the export value, causes an increase of the PI index by 4 times.

\section{CONTIGENCY ANALYSIS, PI EVALUATION}

In the study case of the Albanian power system, the line with the higher value of PI is the line Zemblak-Elbasan2. In some cases when the PI values is very high the solution does not converge, suggesting the operational limits where breached. It is evident that this line is loaded in the case of high export schedules, consequently without this line in operation, violation of operational limits is expected to take place. If the export schedule decreases the critical element is OHL Tirana2-Rrashbull, which has the same PI with Elbasan1-Fier.

Although the analysis is based in the individual grid model, it is assumed that the representation of the flows on tie lines are the best estimate of the system conditions. Even though the results mainly suggest that OHL Elbasan2-Zemblak is a critical element, also tie line Zemblak-Kardia is of the same magnitude critical.

Based on the Transmission System Security analysis using performance indices and comparing the results of all scenarios subject of analyze we can observe that:

The structure of the Albanian Power System is characterized by the concentration of generating capacities in the northern part of the country while the loads are mainly concentrated in the central and southern part of the country. Referring to this structure i.e an extending vertical profile, in the case of high imports and exports the most sever contingencies result in the $400 \mathrm{kV}$ line due to the fact that the entire generation of the Drin river cascade will be concentrated on the four substations respectively Tirana 1, Tirana 2, Elbasan 1 and Elbasan 2. The substation Tirana 2, as it can be seen from single line diagram Fig.1, beside the $400 \mathrm{kV}$ interconnection line with Podgorica and more recently with Kosovo B has many 220 lines $\mathrm{kV}$, which enables it to distribute the incoming high flows, without causing any problems for contingencies. The opposite occurs at the $400 \mathrm{kV}$ substation Elbasan 2, which has a small 
number of lines, hence a small capacity for the distribution of incoming flows, and consequently the more severe contingencies result from the $400 \mathrm{kV}$ interconnection lines of this substation.

So the $400 \mathrm{kV}$ network in the Albanian transmission system extends vertically from north to south (Podgorica 2 - Tirana 2, Elbasan 2 - Zemblak - Kardia), where also the direction of the power flows is from north to south and consequently every interruption of the 400 line $\mathrm{kV}$ Elbasan 2 - Zemblak would significantly endanger transmission system operation.

In the case of regime with small values of interchange (imports or exports) or during balance regime, the contingencies move to $220 \mathrm{kV}$ lines and precisely to Tirana 2 - Rrashbull and Elbasan 1 - Fier or and Rrashbull - Fier lines. Concluding and summarizing it is evident that in the case of small power interchange, large contingencies are in the closed 220 kV loop Tirana 2- Rrashbull-Fier-Elbasan.

Another problem observed during the analysis is the significant drop of the voltage in the southern part of the country, especially in the Fier - Babice line where after each contingencies was observed a significant drop of the voltage, due to the fact that this is an end line.

\section{CONCLUSION}

The results of simulations give a clear picture of the most severe contingencies. Through evaluation of the PI indexes, the Transmission System Operator can make an assessment of the system conditions, regarding operational security.

In the Albanian power system the major part of generation is concentrated in the north part and the biggest generating units are connected to $220 \mathrm{kV}$ network, which redirects all flows at S/s Tirana2, S/s Elbasan2, S/s Elbasan1, S/s Tirana1. From here there are S/s Tirana2 and S/s Elbasan2 which through $400 \mathrm{kV}$ lines allow to push all the flows in case of high export schedules, but due to regional power flows in South East Europe, the direction of the flow is from north to south. Taking into account also the natural flow from Montenegro to Albania together with the flow from $220 \mathrm{kV}$ Albanian generation, the lines Elbasan2-Zemblak-Kardia becomes critical for operational security.

It is worth to note that in the study it is used only the model of the Albanian Power System. In order to achieve a greater accuracy, it is important in the future to use a regional model.

The methodology used in the study, is important also to give the initial conditions for improving the protection setting on the OHL Zemblak-Elbasan2, because such line (400kV OHL Elbasan2-Zemblak) terminating at tie-line $(400 \mathrm{kV}$ OHL Zemblak-Kardia), have different setting based on the import or export schedule.

One of the main projects of the Albanian TSO, is to build the OHL Elbasan2-Bitola, which will increase transfer capability and increase security, consequently decreasing the loading of Elbasan2-Zemblak.

\section{REFERENCES}

[1] Wu L, Gao J, Wang Y, Harley RG. A survey of contingency analysis regarding steady state security of a power system. North American Power Symposium (NAPS). 2017; pp. 1-6.

[2] Arya LD, Choube SC, Kothari DP. Line Outage Ranking for Voltage Limit Violations with Corrective Rescheduling Avoiding Masking. Journal of Electrical Power and Energy Systems. 2001; vol.23, pp.837-846.

[3] Brandwajn V, Lauby MG. Complete bounding for ac contingency analysis. IEEE Trans. On Power Systems. May 1990; Vol. PWRS-4(2), pp. 724-729.

[4] Halpin TF, Fischl R, Fink R. Analysis of automatic contingency selection algorithms. IEEE Trans. On PAS. May 1984; Vol. PAS-103, pp. 938-945.

[5] EPRI: 'Transmission Planning in an Open Access Environment' (EPRI, Palo Alto, CA, 1997)

[6] Rodrigues MS, Souza JCS, Do Coutto Filho MB, Schilling MTh. Automatic Contingency Selection Based on a Pattern Analysis Approach. Proceedings of IEEE International Conference on Electric Power Engineering; 1999, pp. 179.

[7] Gubina F, Debs A, Golob R. Improved Adjoint Network Algorithm for On-line Contingency Analysis. International Journal of Electric Power Systems Research. 1996; vol. 138, pp. 161-168.

[8] Mohamed A, Shaaban A, Kahla A. A Fast Efficient Accurate Technique for Circuit Contingency Evaluation. International Journal of Electric Power Systems Research. 1998; vol. 45, pp. 181-189.

[9] Ozdemir A, Lim JY, Singh C. Contingency screening for steady state analysis by using genetic algorithms. Proceedings of the IEEE PES Summer Meeting. July 2002; pp. 1142 - 1147.

[10] Kamwa I, Robert Grondin R, Loud L. Time- Varying Contingency Screening for Dynamic Security Assessment Using Intelligent-Systems Techniques. IEEE Transactions on Power Systems. August 2001; Vol. 16 (3), pp. 526-537.

[11] Retty H., Thorp JS., Phasor measurement based voltage sensitivities for contingency analysis. IEEE Power \& Energy Society General Meeting. 2015; pp. 1-4.

[12] Sekhar P, Mohanty S. Power system contingency ranking using Newton Raphson load flow method. Proc. Annual IEEE INDICON. 2013; pp. 1-4.

[13] Ejebe GC, Wollenberg BF. Automatic Contingency Selection. IEEE Trans Power Apparatus and Systems. Jan/Feb 1979; vol.PAS-98, No. 1, pp. 97 -109.

[14] Morison K; Wang L; Kundur P. Power system security assessment. IEEE Power Energy Mag. 2004, 2, 30-39.

[15] Dwivedi M, Dhandhia A, Pandya V. Optimization of weighting factors of performance index to improve 
International Journal of Engineering Research and Technology. ISSN 0974-3154, Volume 13, Number 2 (2020), pp. 280-286

(C) International Research Publication House. https://dx.doi.org/10.37624/IJERT/13.2.2020.280-286

contingency ranking. 7th International Conference on Power Systems (ICPS). 2017, pp. 319-322.

[16] Network Code ENSTO-E Operational Security, 2012.

[17] Manual PSSE page 6625, PSS®E 33.1 Linear Network Analysis Program Operation Manual Estimating Severity Rankings for Single Line Outage Contingencies

[18] OST report

[19] ERE Annual Report 2018

[20] Stefopoulos G, Yang A, Meliopoulos S. An Improved Contingency Ranking Method. 35th North American Power Symposium, October 2003. 